\title{
Falando de Corda em Casa de Enforcado: Discriminação Racial no Brasil
}

Karina Fasson

\section{Resumo:}

O presente artigo analisa, tendo como base um referencial teórico sociológico e antropológico acerca das relações raciais no Brasil e nos Estados Unidos, dois casos relacionados à discriminação racial ocorridos no ano de 2009, um em cada respectivo país. O primeiro diz respeito à prisão de um professor da Universidade de Harvard após tentar entrar em sua própria residência. O segundo, à agressão a um funcionário da Universidade de São Paulo por funcionários de um supermercado em Osasco (SP), após ter sido acusado de tentar roubar o próprio carro. Reconstituo, por meio de matérias divulgadas pela imprensa, os dois episódios em questão. Através da comparação entre esses dois acontecimentos -, questões em comum, repercussões e desfechos - avalio alguns aspectos da situação racial em cada país, tentando iluminar, por meio desse quadro, as relações raciais no Brasil.

Palavras-chave: Discriminação racial, relações raciais, estereótipo. 


\section{Introdução}

Desde os primeiros estudos sobre relações raciais no Brasil, como o realizado pelo sociólogo americano Donald Pierson em 1935 na Bahia (PIERSON, I97I), há uma tendência em afirmar que não há preconceito racial no país - ao contrário do que aconteceria então nos Estados Unidos, onde o racismo seria reiterado pelas leis segregacionistas de então. Um dos argumentos mobilizados nesse sentido pelos estudiosos era o de que a ascensão social dos negros e mulatos era possível no Brasil, ao contrário do que se notava nos Estados Unidos, em que as barreiras de classe e raça se sobrepunham.

Teses desse gênero, que se baseavam na exceção e não na regra, foram desarticuladas a partir da década de 1950. Estudos financiados pela UNESCO nesse período mostraram a dificuldade de mobilidade ascendente por parte dos afro-descendentes, denunciando a existência do preconceito racial no Brasil.

Ainda assim, notamos que aquela tendência surgida na década de I930 continuou a se reproduzir até a contemporaneidade no nosso país. Livros como o do sociólogo Ali Kamel (2006) endossam visões semelhantes àquela de Pierson, afirmando que desde a abolição, não há barreiras que impeçam a ascensão social do negro. O que geraria preconceito seria a pobreza, e não a cor da pele, dada a existência, segundo ele, de um "classismo" no Brasil.

Quando se pensa em discriminação racial em nosso país, não se deve pensar apenas na existência ou não da possibilidade de ascensão social para os afrodescendentes. Não pretendo entrar no mérito da existência ou não de dificuldades na realização de tal processo, discussão também importante quando se fala sobre relações sociais no Brasil. Apenas defendo que, para além dessa questão, está outra nem sempre lembrada: a aceitação dessa ascensão por parte da sociedade. Casos como o de Januário Santana, que será aqui tratado, mostram que ascender é possível, mas que não necessariamente entende-se essa ascensão como verdadeira. $\mathrm{E}$ as consequências disso podem ir além de simples mal-entendidos, culminando em atos de violência e humilhação.

Esse artigo está dividido em duas partes. Primeiramente, situo, com base em notícias divulgadas por veículos de comunicação online, dois casos de discriminação racial ocorridos em 2009 no Brasil e nos Estados Unidos. O primeiro diz respeito à prisão de Henry Gates, professor da Universidade de Harvard, após tentar entrar em sua própria residência. $O$ segundo, referido acima, consiste na agressão a um funcionário da Universidade de São Paulo por seguranças de um supermercado em Osasco (SP), após ter sido acusado de tentar roubar o próprio carro. 
Num segundo momento, analiso os dois casos isoladamente e paralelamente com base em um referencial teórico sociológico e antropológico, pensando nas questões do racismo, da estereotipia e das relações raciais em cada país. Levando em conta o desenvolvimento e desfecho de cada caso, o presente artigo tem como objetivo iluminar certos aspectos acerca da situação racial brasileira.

\section{O Caso Henry Gates}

Em I6 de julho de 2009, o professor da Universidade de Harvard Henry Louis Gates Jr. foi detido dentro de sua residência na cidade de Cambridge, em Massachussets, Estados Unidos. Gates havia chegado de viagem após passar uma semana na China filmando um documentário. Ao tentar entrar em casa, não teve sucesso em abrir a porta; pediu então ajuda ao motorista que o havia levado. Depois de cerca de 15 minutos, conseguiu entrar em casa (GI, Professor de Harvard é preso, solto e acusa polícia de racismo, 2I/07/2009).

Nesse meio tempo, contudo, uma vizinha (ou alguém que estava passando, as versões variam), telefonou para a polícia dizendo que havia dois homens negros tentando invadir uma casa. A polícia teria chegado e pedido ao professor para sair de sua casa e apresentar documentos. Gates teria apresentado documentos de identificação provando que estava em sua própria casa e se recusado a sair. Teria também solicitado a identificação do policial, que o teria ignorado. Mesmo assim, foi detido pela acusação de invadir uma casa e fazer bagunça em excesso e liberado após ser fichado na delegacia (THOMPSON, Krissah. Scholar Says Arrest Will Lead Him To Explore Race in Criminal Justice. The Washington Post, 22/07/2009). No dia 2I, a polícia reconheceu publicamente o erro na prisão e avisou que a acusação contra o Gates fora retirada.

O caso gerou debates nos EUA e no mundo todo acerca das relações raciais. A declaração do presidente norte-americano, no dia 22 seguinte, fomentou mais as discussões. Ao ser perguntado numa coletiva de imprensa da opinião sobre o caso, Obama disse: "Primeiro, cada um de nós ficaria bem bravo. Segundo, a ação da polícia de Cambridge foi estúpida por prender alguém dentro da própria casa. E terceiro, é um fato que afroamericanos e latinos são parados pela polícia de forma desproporcional. Em resposta, Crowley, o sargento responsável pelo caso, disse que o presidente deveria ter medido suas palavras e que deveria se informar melhor sobre os fatos antes de dar declarações - o policial afirmou ter sido xingado pelo professor. (GI, Obama diz que polícia foi 'estúpida' ao prender amigo professor de Harvard. GI, 23/07/2009) No dia 24, após as exigências de desculpas por parte da polícia, Obama afirma que deveria ter 
escolhido melhor suas palavras. Disse, contudo, que acha que o policial exagerou ao pedir que o professor saísse de sua casa, assim como também o professor talvez tenha realmente exagerado em sua reação. Afirmou que se o caso chamou tanta atenção, é sinal de que envolve assuntos que ainda são delicados nos EUA. Se isso aconteceu, é porque a questão racial ainda é um problema na sociedade americana, afirmou em seu discurso. Para solucionar o caso, então, convida o professor e o policial para uma cerveja na Casa Branca no dia 30, juntamente com ele e o vice-presidente norte-americano (Obama recua e chama brigões para uma cerveja na Casa Branca. GI, 24/07/2009; Obama marca cervejada dos brigões para quinta-feira na Casa Branca. GI, 28/07/2009). Segundo declarações posteriores, os dois teriam se entendido na ocasião. O professor de Harvard fez até brincadeiras sobre o caso, dizendo que se ofereceu para colocar os filhos do policial na faculdade, se ele não o prendesse mais (Depois da cervejada na Casa Branca, professor faz brincadeiras sobre prisão. GI, 03/08/2009).

\section{O Caso Januário Santana}

Em 07 de agosto de 2009, o vigilante e eletricista Januário Alves de Santana foi agredido no Hipermercado Carrefour de Osasco (SP) enquanto aguardava sua família, que fazia compras na loja. Ao tentar entrar em seu próprio carro, um Ford Ecosport, após ter saído dele por ouvir o barulho de alarme de uma moto, foi abordado pelos seguranças do estacionamento, que o acusaram de tentar roubar o veículo. Foi levado para uma sala próxima à entrada da loja, onde foi espancado por cinco seguranças. Em entrevista, Januário disse que os seguranças o ameaçavam dizendo "Cala a boca seu neguinho", e riam quando ele dizia que o carro era seu. (Homem negro espancado, suspeito de roubar o próprio carro. Afropress, I3/08/2009).

Com a chegada da polícia, a agressão por parte dos seguranças teria cessado. Contudo, o policial que foi atender a ocorrência também teria agido com preconceito, dizendo a Januário "Você tem cara de que tem pelo menos três passagens. Pode falar. Não nega. Confessa que não tem problema" (Homem negro espancado, suspeito de roubar o próprio carro. Afropress, I3/08/2009). Depois de conferir a documentação do carro, que estava no nome da esposa do agredido, a polícia deixou o local sem tomar providências em relação ao ocorrido ou prestar socorro. $\mathrm{O}$ caso foi registrado no dia seguinte, 08 , na $9^{\circ}$ Delegacia de Polícia de Osasco. A vítima teve que realizar uma cirurgia por ter sofrido uma fratura na face durante a agressão, e chegou a ter que cancelar seu depoimento à polícia devido a seu estado de saúde. (Cliente agredido em mercado em SP deve passar por cirurgia nesta semana. Folha Online, 25/08/2009) 
O supermercado divulgou ter afastado a gerência da loja e a empresa de segurança no dia 20 de agosto, e afirmou ainda ter solicitado "máximo rigor na apuração dos fatos" (Folha Online, 31/08/2009). Em relação à polícia, foi aberto um inquérito interno para averiguar se os policiais foram negligentes ao atenderem Januário no supermercado. Em março de 20I0, foi realizado um acordo entre o supermercado e a vítima, que aceitou receber uma indenização de valor não divulgado. $\mathrm{O}$ inquérito, entretanto, não havia sido concluído até a ocasião (Afropress, I9/03/2010; Folha Online, I9/03/2010).

\section{Racismo e Estereotipia}

Em relação ao caso do professor de Harvard, um leitor fez o seguinte comentário numa reportagem do jornal Washington Post que relatava o ocorrido (THOMPSON, Krissah. Scholar Says Arrest Will Lead Him To Explore Race in Criminal Justice. The Washington Post, 22/07/2009).

Então homens negros estão sendo discriminados, hummm, talvez isso ocorra porque eles cometem a maioria dos crimes. Quer mais respeito? Aja como se tivesse algum senso, e para Mr. Gates, você escreve sobre e dá palestras sobre como os negros são tratados na América, suas ações mostraram a razão pela qual as coisas são como são, você apenas mantém o pote do racismo fervendo, que vergonha. (comentário de nlbi954, postado em 24/07/2009 às I:I6:II PM, tradução nossa)

Nessa mesma reportagem, há um trecho de uma fala do professor comentando sobre a atitude da mulher que ligou para a polícia e a ação da corporação:

Eu estou feliz que alguém se preocupou o suficiente com minha propriedade para relatar o que achou ser uma invasão inconveniente. Se ela visse alguém amanhã que parecesse estar tentando invadir, eu gostaria que ela discasse 9II[número para casos de emergência, nos EUA]. Eu gostaria que a polícia viesse. O que eu não gostaria é de ser presumido culpado. Essa foi a questão. Não importou como eu estava vestido. Não importou como eu falava. Não importou como eu me comportei. Aquele homem [Crowley] estava convencido de que eu era culpado. (THOMPSON, Krissah. Scholar Says Arrest Will Lead Him To Explore Race in Criminal Justice. The Washington Post, 22/07/2009) 
Falando de Corda em Casa de Enforcado: Discriminação Racial no Brasil

Podemos confrontar essas duas falas com aquelas feitas pelo advogado para o jornal Folha Online e pela esposa de Januário Santana para a agência de informações Afropress:

O negro com aparência humilde é o suspeito padrão. Mesmo ensangüentado, todo maltratado, ele foi tratado como suspeito até mesmo pelos policiais militares que atenderam a ocorrência, e teve que provar que o carro era seu para deixar o estacionamento. [...] Eles [a polícia e os seguranças do mercado] pensaram que jamais um negro poderia dirigir um EcoSport (Folha Online, 2I/08/2009).

A mulher disse que o EcoSport, que está sendo pago em 72 parcelas de $R \$$ 789, 00, vem sendo fonte de problemas para a família desde que foi comprado há dois anos. 'Toda vez que ele sai a Polícia vem atrás de mim. 'Esse carro é seu?' Até no serviço a Polícia já me abordou. Meu Deus, é porque ele é preto que não pode ter um carro EcoSport?”, se pergunta. (Afropress, I3/08/2009)

O que todas essas falas mostram muito fortemente é o estereótipo que envolve a figura do negro, tanto nos EUA como no Brasil. No comentário do leitor do jornal americano, fica clara a associação entre negro e crime - além do que o leitor joga de volta a acusação de racismo para sua vítima. Na fala de Gates, está implícita a idéia de que o policial o considerou criminoso sem considerar qualquer outro fator por conta de seu fenótipo. Nas falas do advogado e da esposa de Januário Santana, é flagrante a associação do negro com a pobreza e o crime, na ideia de que um homem negro só poderia ter um carro como o de Januário se o tivesse roubado. Como problematizar esse tipo de associação entre "raça" e aspectos sociais, comum aos dois casos analisados?

A literatura aponta que tal associação é realizada há muito tempo. Munanga (2004) afirma que, no século XVIII, os filósofos iluministas, diante de uma diversidade humana recém-descoberta, passam a utilizar o conceito de raça existente nas ciências naturais para dar conta de explicar tal variedade de acordo com a razão, fugindo das explicações teológicas. A partir de então, utilizou-se o conceito de raça não apenas para classificar a diversidade, mas para hierarquizá-la - daí sim surge o problema em relação às raças, com a teoria pseudo-científica da raciologia no século $\mathrm{XX}$, e a propagação, para além da academia, dessas doutrinas que tinham como base a hierarquia das raças. 
Infelizmente, desde o início, eles se deram o direito de hierarquizar, isto é, de estabelecer uma escala de valores entre as chamadas raças. E o fizeram erigindo uma relação intrínseca entre o biológico (cor da pele, traços morfológicos) e as qualidades psicológicas, morais, intelectuais e culturais. Assim, os indivíduos da raça "branca" foram decretados coletivamente superiores aos da raça "negra" e "amarela", em função de suas características físicas hereditárias [...] que, segundo o que pensavam, os tornavam mais [...] aptos para dirigir e dominar as outras raças, principalmente a negra, a mais escura de todas, considerada, por isso, como a mais estúpida, mais emocional, menos honesta, menos inteligente e, portanto, a mais sujeita à escravidão e a todas as formas de dominação (MUNANGA, 2004, p. 2I).

Entretanto, sabe-se desde o século passado, graças aos estudos na área da genética, que não existem raças biológicas. Experimentos mostraram que indivíduos considerados de uma mesma raça podem ter patrimônios genéticos mais distantes do que outros dois considerados de raças distintas. Isso não impede, contudo, que encontremos hoje em dia manifestações de racismo. Segundo Munanga (2004), o conceito de raça que impera atualmente é ideológico, escondendo as relações de poder e dominação que nele estão implícitas:

No imaginário e na representação coletivos de diversas populações contemporâneas existem ainda raças fictícias e outras construídas a partir das diferenças fenotípicas como a cor da pele e outros critérios morfológicos. É a partir dessas raças fictícias ou raças sociais que se reproduzem e se mantém os racismos populares. (MUNANGA, 2004, p. 22)

O racismo é, então, de acordo com Munanga, "uma crença na existência das raças naturalmente hierarquizadas pela relação intrínseca entre o físico e o moral, o físico e o intelecto, o físico e o cultural" (MUNANGA, 2004, p. 24). A prática está associada à noção de estereótipo, que opera no sentido de representar a diferença racial. Segundo Hall (I997), o estereotipo reduz, essencializa e fixa a noção que temos do outro: na visão de quem estereotipa, o sujeito é reduzido àquilo que o estereótipo diz que ele é. $\mathrm{O}$ racismo atua no sentido de criar e legitimar certos estereótipos, portanto.

Percebemos o estereótipo em relação ao negro em trabalhos como o de Oracy Nogueira (I985), que utiliza o conceito de incongruência de status ao tratar dos vários fatores que importariam para classificar um sujeito numa sociedade tida como de classes (em oposição a uma sociedade de castas, como era considerada 
a norte-americana, onde haveria uma linha de cor que impediria a mobilidade social dos grupos negros). Fazendo uma ressalva à afirmação de outros autores que acreditavam que a cor da pele seria apenas mais um dos fatores para classificar o status de um indivíduo, Nogueira lembra: "Embora a cor ou as marcas raciais representem apenas um dos componentes do status no Brasil, deve-se atentar para o fato de que a aparência negróide numa pessoa com outros fatores favoráveis é sempre um fator de incongruência de status" (NOGUEIRA, I985, p. 22) Deixando mais claro seu argumento, ele nos dá um exemplo interessante para pensar as situações analisadas:

Duvido que um brasileiro branco de camada média para cima não faça diferença entre um pobre preto e outro branco. Diante de crianças pobres, pretas e brancas, por exemplo, sua tendência será para lastimar mais a sorte das últimas. (...) A miséria é menos surpreendente em negros do que em brancos. (NOGUEIRA, I985, p. 22)

Nesse sentido, vemos que nas situações analisadas o negro, tanto no Brasil quanto nos EUA, tem sua essência reduzida ao crime à pobreza. Ao que tudo indica, para o policial, um homem negro não poderia ser o dono daquela casa. Para os guardas e os policiais no supermercado, um homem negro não poderia ser o dono de um Ecosport. Isso porque, para eles, o negro é visto como inferior e associado e reduzido a aspectos negativos, não podendo fugir disso. É algo que foi introjetado no imaginário coletivo da sociedade de cada um desses países há séculos através de maneiras distintas, mas que, como se pode ver, continuam atuando.

\section{Relações Raciais no Brasil e nos EUA}

Refletindo sobre a repercussão de cada um dos dois casos e a maneira com que foram solucionados, podemos pensar sobre as relações raciais em cada um dos países em questão.

No caso da prisão do professor de Harvard, a repercussão foi imensa, tendo sido o caso discutido pelo mundo todo. Não se pode deixar de lado, obviamente, o fato de que se tratava de um professor de uma das universidades mais prestigiadas do mundo. Ainda assim, o envolvimento do presidente e a rapidez para a solução do caso mostram que a etiqueta no que diz respeito às relações raciais nos EUA é diferente daquela existente no Brasil. 
Apesar da idéia de que o Brasil seja uma "democracia racial", um país onde as diferentes etnias convivam em condições de igualdade, já ter caído por terra há décadas - tanto na academia, por meio de trabalhos que demonstram que tal ideia é falaciosa, como na sociedade em geral, através de casos que demonstram a ocorrência de discriminação racial e de movimentos que o denunciam -, podemos notar, tendo em vista a repercussão desses dois casos em nosso país, como ainda vivemos sob a sombra das etiquetas de uma suposta democracia racial. Em relação à repercussão do caso americano no Brasil, chamou a atenção o fato de os veículos de comunicação terem se atido a detalhes menores da resolução do caso pelo presidente norte-americano. Enquanto nos EUA havia uma expectativa muito grande para o encontro que tentaria solucionar a situação, inclusive com contagem regressiva realizada por duas das principais redes de televisão norte-americanas (GI, 30/07/2009), no Brasil, muito se falou na imprensa sobre a polêmica em torno da marca da cerveja que foi servida no encontro de reconciliação entre Henry Louis Gates Jr. e o sargento Crowley (cf., por exemplo, Exame, 30/07/2009): o fato de Obama ter bebido uma cerveja de marca BelgoBrasileira parece ter tido mais impacto em diversos veículos da imprensa do que a mediação do conflito em si. Essa diferença é significativa no sentido em que reflete, em partes, a diferença nas relações raciais em ambos os países.

Nos EUA, em que a segregação racial não era apenas existente, mas reconhecida por lei até meados dos anos I960, formou-se uma etiqueta de relações raciais distinta da brasileira. Pode-se levantar a hipótese de que o fato de o país ter vivido abertamente sob um regime segregacionista tenha proporcionado um espaço maior na sociedade para que se fale de tais temas - afinal, eles sempre foram explicitados. E, sobretudo, que haja uma preocupação por parte do governo, que no passado legitimou essas práticas, para que isso não ocorra mais, também tendo em vista o potencial dos conflitos raciais no país.

Nogueira (I985), entre outros, aponta que definição de branco e negro no Brasil e nos EUA traz efeitos distintos para as relações raciais nos dois países. Enquanto nos EUA, apenas duas classificações são possíveis (branco ou negro), no Brasil, há no meio desses dois grupos o mulato, que, nos termos de Degler, seria a "válvula de segurança": o mulato estaria dissociado do negro, e, por meio da aquisição de atributos como educação e riqueza, poderia se aproximar mais do grupo branco. Daí a dificuldade de criar uma solidariedade entre negros e mestiços no país, o que minimizaria o conflito racial suscitado pelo preconceito. Nos EUA, portanto, a classificação racial permitiu a formação do que se poderia chamar de identidade negra, o que possibilitou uma luta contra o preconceito mais forte em relação ao caso do Brasil. Esse pode ser pensado como outro ponto 
que explica a rápida ação no sentido de resolver o caso envolvendo o professor norte-americano.

Casos anteriores mostram o potencial do conflito inter-racial suscitado pelas manifestações de preconceito, e podem ser pensados também como relacionados à rápida solução do episódio aqui analisado. Em I99I, o taxista Rodney King foi brutalmente espancado por policiais em Los Angeles, sob a acusação de dirigir em alta velocidade. Após a absolvição dos policiais envolvidos, em I992, iniciou-se uma série de motins em Los Angeles, que resultaram em 53 mortos e 2.383 feridos (Wikipedia).

No Brasil, no que diz respeito à produção acadêmica sobre o tema, a convivência entre brancos e negros era endossada como harmoniosa desde os anos I930 por autores como Gilberto Freyre (2008), em referência à escravidão, e, posteriormente, se desdobrou na noção de que não havia linha de cor de impedisse a mobilidade social de negros no Brasil, em trabalhos como o de Donald Pierson(I97I). Essas teses, na academia, refletem a crença que existia na sociedade (não só brasileira, mas por todo o mundo) de que não havia preconceito racial no país. Ainda em relação à academia, notamos que essa crença foi desmontada posteriormente, por meio de estudos que denunciam a existência do preconceito racial e revelam as dificuldades de ascensão do negro na sociedade brasileira, tendo como marco importante parte dos estudos de relações raciais realizados pelo projeto UNESCO entre I950 e I953 - como o de Florestan Fernandes (2008); posteriormente, outros trabalhos foram ainda mais incisivos nesse sentido, como o de Hasenbalg (I979), que, ao contrário de Fernandes, não vê o preconceito racial como funcional do sistema capitalista. Isso era visível na sociedade como um todo, também, por meio da articulação de movimentos que denunciavam a existência do racismo e lutavam por igualdade de condições. Um marco importante, nesse sentido, seria a formação do Movimento Negro Unificado (MNU) em I978, criando o que Telles (2003) chama de "política negra moderna" em contraposição aos movimentos anteriores, que vê como de cunho culturalista.

Mesmo com a derrubada da noção de paraíso racial, contudo, percebemos mais contemporaneamente que ainda há certa resistência em tratar do assunto do preconceito racial no nosso país. Autores como Telles (2003), por exemplo, tratam do temor do governo brasileiro, no final dos anos I990, de ver desmoronado o mito da democracia racial na Terceira Conferência Mundial contra o Racismo, Discriminação Racial, Xenofobia e Outras Formas de Intolerância ocorrida em 200I, quando o país se recusa a sediar a reunião preparatória na América Latina.

Esse exemplo mostra a dificuldade que há, ainda atualmente no Brasil, de se falar sobre raça e racismo, e reflete a etiqueta do caráter disfarçado da 
discriminação no país. A referencia que Nogueira faz a Frazier em relação a um trabalho do sociólogo nos anos 1930 pode ser transposta para a atualidade: "Há no Brasil pouca discussão a respeito da situação racial ou de cor. Parece haver um entendimento não expresso entre todos os elementos da população para não discutir a situação racial, pelo menos como fenômeno contemporâneo." (NOGUEIRA apud FRAZIER, I985, p. 42)

Sob a luz dessas ideias, pode-se pensar a repercussão de ambos os casos no nosso país. O fato de o caso americano ter sido esvaziado de conteúdo por parte da imprensa revela o tabu que existe ainda em tratar desses assuntos no Brasil. A repercussão do caso de Januário Santana é também paradigmática nesse sentido: o caso começou a ser noticiado pelos principais jornais online do Brasil mais de IO dias após o ocorrido (a exemplo da Folha Online, que noticiou o episódio I2 dias depois) - diferentemente do americano, que, em pouco mais do que isso (I 4 dias), havia sido não apenas noticiado como também solucionado. Além disso, das duas manifestações em protesto ao episódio no supermercado, apenas uma foi noticiada por alguns dos principais veículos online - notícias mais completas puderam ser encontrados apenas em veículos independentes de notícia.

O caso parou de ser noticiado cerca de três semanas após o ocorrido pelos principais jornais online, voltando a ser tratado apenas em março de 20IO, em ocasião de seu desfecho. Sete meses depois, houve a realização de um acordo entre o supermercado e Januário pelo pagamento de uma indenização à vítima, de valor não divulgado ( $G I$, I9/03/20I0). Contudo, o caso ainda não teve solução no âmbito policial: o inquérito na delegacia onde foi registrado ainda não foi concluído, o que impede o caso de ir a julgamento (Afropress, 20/03/2010). Pode-se relacionar essa demora com a falta de pressão por parte da opinião pública, o que refletiria, mais uma vez, a dificuldade em se discutir assuntos relacionados à discriminação racial em nosso país.

Alguns comentários de notícias relacionadas ao caso também parecem evitar falar do assunto, desviando o problema para outras dimensões - afinal, usando o ditado popular empregado por Oracy Nogueira (NOGUEIRA, I985, p. 53) em referência à etiqueta racial brasileira, "em casa de enforcado, não se fala em corda". A seguir, um exemplo disso no comentário de um leitor do Estadão Online (22/08/2009), que desvia o problema do racismo para a questão do treinamento dos seguranças:

Este caso serviu para alertar um problema sério que infelizmente ocorre em nosso país: a falta de preparo dos profissionais de segurança destas empresas de segurança terceirizadas que não só o Carrefour, mas todas as grandes empresas, inclusive as públicas contratam, como é o caso da CPTM e hospitais públicos. As 
empresas que prestam estes serviços, pagam salário de fome para estes funcionários e não lhes dão nenhum treinamento de como tratar as pessoas. Eu já presenciei vários casos em que estes "profissionais", utilizando apenas o critério da aparência, abordam pessoas ou maltratam - nas causando constrangimento. Eu mesmo já fui vítima, quando entrei no Magazine Luiza para verificar o preço de um artigo, e o segurança ficou no corredor onde eu estava o tempo todo para ver o que eu estava fazendo. Quase que perguntei para ele se havia algum problema, mas preferi sair e nunca mais entrar nesta loja. E olha que eu estava bem vestido, sou branco e loiro. (M. R. M., 23/o8/og)

Por fim, a resistência em se tratar do assunto no país se revela mais uma vez por meio da mídia, que não noticiou o encontro de Januário Santana com o ministro Edson Santos, da Secretaria Especial de Políticas de Promoção da Igualdade Racial em 02/09/2009. As únicas menções que a imprensa online convencional faz são de um possível encontro com o ministro, nada foi dito sobre o acontecimento dessa reunião por parte de tais veículos. Pude encontrar uma reportagem a respeito apenas num veículo de notícias independente (Afropress, 03/og/2009).

Ainda assim, é significativo notar que, apesar da resistência por parte da sociedade de tratar do assunto (o que verificou-se por meio da repercussão na mídia e da falta de pressão expressiva por parte da opinião pública para a resolução do caso), o governo está tentando quebrar esse silêncio: "Os participantes destacaram que o encontro foi um marco histórico: foi a primeira vez que um ministro de Estado, diante de um caso de agressão racista, tomou a iniciativa de assumir a defesa e a solidariedade à vítima." (Afropress, 03/og/2009).

\section{Referências Bibliográficas:}

Artigos de publicações online e sites consultados:

Professor de Harvard é preso, solto e acusa polícia de racismo. GI, 2I/O7/2009. Disponível em: 〈http://gI.globo.com/>. Acesso em: 28/II/2009.

THOMPSON, Krissah. Scholar Says Arrest Will Lead Him To Explore Race in Criminal Justice. The Washington Post, 22/07/2009. Disponível em: $<$ http://www.washingtonpost.com/>. Acesso em: 27/I2/2009. 
Obama diz que polícia foi 'estúpida' ao prender amigo professor de Harvard. GI, 23/07/2009. Disponível em:〈http://gI.globo.com/〉. Acesso em: 28/12/2009.

RAZZI, Elizabeth. Breaking Into Your Own House. The Washington Post, 23/07/2009. Disponível em: <http://voices.washingtonpost.com/> . Acesso em: 27/12/2009.

Obama recua e chama brigões para uma cerveja na Casa Branca. GI, 24/07/2009. Disponível em: <http://gI.globo.com/>. Acessado em: 28/12/2009.

Obama marca cervejada dos brigões para quinta-feira na Casa Branca. GI, 28/07/2009. Disponível em: 〈http://gi.globo.com/> . Acessado em: 27/12/2009.

Depois da cervejada na Casa Branca, professor faz brincadeiras sobre prisão. GI, 03/08/2009. Disponível em: 〈http://gI.globo.com/〉. Acesso em: 27/12/2009.

Cerveja da belgo-brasileira ABInBev gera polêmica na Casa Branca. Exame, 30/07/2009. Disponível em: 〈http://portalexame.abril.com.br/>. Acesso em: $04 / 12 / 2009$.

Homem negro espancado, suspeito de roubar o próprio carro. Afropress, 13/08/2009. Disponível em: 〈http://www.afropress.com/〉. Acesso em: $30 / 1 \mathrm{II} / 2009$

Vigilante diz ter sido agredido por seguranças de loja do Carrefour em Osasco (SP). Folha Online, I9/08/2009. Disponível em: <http://wwwI.folha. uol.com.br/>. Acesso em: 29/II/2009.

NOVAES, Marina. Confundido com ladrão, vigilante agredido em mercado diz ter sido vítima de racismo. Folha Online, 19/08/2009. Disponível em: <http://wwwI.folha.uol.com.br/>. Acesso em: 29/II/2009.

Carrefour afasta gerência de loja em Osasco (SP) após agressão. Folha Online, 2I/08/2009. Disponível em: 〈http://wwwI.folha.uol.com.br/>. Acesso em: 29/II/2009. 
NOVAES, Marina. Carrefour afasta vigia após denúncia de agressão a cliente em Osasco (SP). Folha Online, 20/08/2009. Disponível em: <http:// wwwI.folha.uol.com.br/>. Acesso em: 29/II/2009.

Manifestantes protestam contra racismo no Carrefour de Osasco. Estadão Online, 22/08/2009. Disponível em: 〈http://www.estadao.com.br/〉. Acesso em: OI/I2/2009

Cliente agredido em mercado em SP deve passar por cirurgia nesta semana. Folha Online, 25/08/2009. Disponível em: <http://wwwI.folha.uol.com.br/>. Acesso em: 29/II/2009.

Cliente agredido em supermercado em Osasco (SP) cancela depoimento à polícia. Folha Online, 25/08/2009. Disponível em: <http://wwwI.folha.uol. com.br/>. Acesso em: 29/II/2009.

Polícia abre inquérito para apurar agressão em supermercado de Osasco (SP). Folha Online, 26/08/2009. Disponível em:< http://wwwI.folha.uol.com. br/>. Acesso em: 29/II/2009.

$\mathrm{OAB}$ repudia agressão a vigilante em loja do Carrefour. Folha Online, 3I/O8/2009. Disponível em: < http://wwwI.folha.uol.com.br/>. Acesso em: $30 / \mathrm{II} / 2009$.

Você não está só, diz ministro à vítima de violência racista. Afropress, 03/o9/2009. Disponível em: 〈http://www.afropress.com/〉>. Acesso em: $05 / 12 / 2009$

Carrefour indeniza cliente confundido com ladrão em loja da grande São Paulo. GI, I9/03/20IO. Disponível em: 〈http://gi.globo.com/〉. Acesso em: 20/03/2010.

Carrefour/Januário: acordo celebra vitória do diálogo. Afropress, I9/og/2010. Disponível em: 〈http://www.afropress.com〉. Acesso em: 2I/O3/20IO.

RODNEY KING. In: WIKIPEDIA, the free enciclopedia. Flórida: Wikimedia Foundation, 2009. Disponível em: <http://en.wikipedia.org/wiki/ Rodney_King>. Acesso em: 20 nov. 2009. 
Livros:

FERNANDES, Florestan. A integração do negro na sociedade de classes. São Paulo, Globo, 2008.

FREYRE, Gilberto. Casa-grande \& Senzala: formação da família brasileira sob o regime da economia patriarcal. São Paulo, Global, 2008.

HALL, Stuart. The Spectacle of the 'Other'. In: Representation: Cultural Representations and Signifying Practices. Ed. Hall. London: Sage, I997., pp. 223-290.

MUNANGA, Kabengele. Uma abordagem conceitual das noções de raça, racismo, identidade e etnia. In: André Augusto P. Brandão (org.). Programa de educação sobre o negro na sociedade brasileira. Editora da Universidade Federal Fluminense, Niterói, 2004, pp. I7-34.

NOGUEIRA, Oracy. Tanto preto quanto branco: estudos de relações raciais. São Paulo, T. A. Queiroz, I985, pp. I-66.

PIERSON, Donald. Brancos e Pretos na Bahia (Estudo de contacto racial). São Paulo, Editora Nacional, I97I.

TELLES, Edward. Racismo à brasileira - Uma nova perspectiva sociológica. Capítulo 3, pp. 69-IO2. Rio de Janeiro: Ed. Relume-Dumará, 2003.

Karina Fasson é graduanda em Ciências Sociais pela USP.

E-mail: karinafasson@usp.br 